\title{
SÍLICA DA CASCA DO ARROZ OBTIDA ATRAVÉS DE ULTRASSOM ASSISTIDO PARA ADSORÇÃO DO CORANTE VIOLETA DE METILA
}

\author{
A. M. CUNHA ${ }^{1}$, E. CHAVES PERES ${ }^{1}$ e G. L. DOTTO ${ }^{1}$ \\ ${ }^{1}$ Universidade Federal de Santa Maria, Departamento de Engenharia Química \\ E-mail para contato: anaelisemuller@gmail.com
}

\begin{abstract}
RESUMO - O presente trabalho visou a remoção do corante violeta de metila utilizando sílica de casca de arroz preparada via ultrassom assistido. Para fins de comparação, utilizou também a sílica obtida via processo convencional. Para comparação dos adsorventes foram utilizados os dados de caracterização no analisador de área superficial e da microscopia eletrônica de varredura. Além disso, foram analisadas as isotermas e a termodinâmica de adsorção. Verificou-se um aumento de $30 \%$ na área superficial, quando a sílica foi obtida via ultrassom assistido. A capacidade máxima de adsorção foi encontrada na temperatura de $45^{\circ} \mathrm{C}$ com remoção de aproximadamente $98 \%$ de corante. Outros resultados encontrados foram os dados termodinâmicos da adsorção $\left(\Delta H, \Delta G^{0}, \Delta S\right)$, demonstrando que o processo de adsorção foi endotérmico.
\end{abstract}

\section{INTRODUÇÃO}

A remoção de corantes de efluentes industriais tornou-se um dos principais problemas ambientais considerando que mesmo pequenas quantidades de corante na água podem ser tóxicas e visíveis (Chiou, 2004). Entre estes corantes, encontra-se o violeta de metila 2B, o qual também é empregado como agente bacteriostático e desinfetante da pele em seres humanos e animais (Santos et al, 2012). Considera-se ser necessária uma descoloração sempre que a concentração de corante no curso de água exceder 5mg/L (Quadros, 2005). A adsorção é uma técnica utilizada para a purificação por meio de adsorventes, os quais podem reter moléculas em sua superfície. Possui como vantagens a facilidade de operação e a alta eficiência (Weber et al, 1978). A sílica é um adsorvente resultante da queima da casca do arroz e é composta principalmente por dióxido de silício (Xiong et al, 2009). Tendo em vista a crescente produção de arroz no Brasil, a sílica se apresenta como um adsorvente potencialmente viável para o uso em tratamento de efluentes. No entanto, é preciso submeter o adsorvente a métodos efetivos de tratamento para aumentar sua pureza e área superficial. Um método alternativo é a modificação com ultrassom. Nesse trabalho, a sílica modificada com ultrassom foi utilizada para a remoção de violeta de metila $2 \mathrm{~B}$ de soluções aquosas e foram investigados os efeitos da temperatura e a termodinâmica.

\section{MATERIAL E MÉTODOS}

\subsection{Obtenção do adsorvente}


O adsorvente escolhido para este estudo foi a sílica, obtida a partir da casca do arroz. A casca é proveniente do arroz do tipo Oryza Sativa da variedade indica de casca com a coloração marrom. Para chegar ao adsorvente final, a casca de arroz passou por cinco tratamentos: lavagem, secagem, queima, lixiviação (normal e acompanhada com ultrassom) e secagem da sílica. A primeira etapa consistiu na lavagem na casca de arroz com água destilada que remove as impurezas superficiais. Após, o material foi seco na estufa durante 24 horas na temperatura de $60^{\circ}$. A casca de arroz foi queimada na mufla (Ind. Magnus Modelo 1109) durante 6 horas, com a temperatura de $600^{\circ} \mathrm{C}$ para queimar totalmente a matéria orgânica.

Na lixiviação, há um aumento da pureza da sílica, pois, esta retira outros óxidos presentes na casca. O processo foi realizado com o ultrassom UP200HT Hielscher (Ltda) na potência de $160 \mathrm{~W}$ e temperatura de $80^{\circ} \mathrm{C}$, adicionou-se $10 \mathrm{ml}$ de $\mathrm{HCl}$ (Sigma-Aldrich) $10 \%$ (já diluído em água) à amostra e o tempo estipulado para a operação foi de 10 minutos. $\mathrm{O}$ material final foi lavado com água deionizada a fim de remover substâncias presentes na superfície da amostra sólida. Após, a sílica permaneceu na estufa durante 24 horas para secagem. Finalmente, a amostra foi analisada no analisador de área superficial (Micromeritcs - ASAP 2020) e no MEV (Jeol, JSM, 6060).

\subsection{Ensaios de adsorção}

Para o preparo das soluções de cristal violeta, utilizou-se violeta de metila $2 \mathrm{~B}$ $\left(\mathrm{C}_{25} \mathrm{H}_{30} \mathrm{ClN}_{3}\right)$, fornecido pela INLAB Ltda, e água deionizada. Primeiramente foi preparada uma solução de $1 \mathrm{~g} \mathrm{~L}^{-1}$ de violeta cristal que foi diluída para preparação das soluções presentes neste trabalho. Na realização dos experimentos de adsorção do corante violeta cristal pela sílica padrão e modificada por ultrassom, foram realizados testes em batelada em banho termostático agitado (Dist LTDA), com agitação constante de $200 \mathrm{rpm}$. A massa do adsorvente foi fixada em 0,05g. As soluções continham o volume total de $50 \mathrm{~mL}$ e pH 10 . Para analisar o efeito da temperatura, variou-se a temperatura $\left(25-45^{\circ} \mathrm{C}\right)$ e a concentração (50-500) $\mathrm{mg} \mathrm{L}^{-1}$ de corante. Na correção do $\mathrm{pH}$, utilizaram-se soluç̃̃es $0,1 \mathrm{~mol} \mathrm{~L}^{-1} \mathrm{de} \mathrm{NaOH}$, e para medi-lo, foi utilizado um pHmetro digital (Quimis LTDA). Após a adsorção, a concentração restante de violeta cristal na solução foi determinada no espectrofotômetro UVmini-1240 (SHIMADZU Ltda). A capacidade de adsorção foi obtida pela equação 1.

$$
\mathrm{q}_{\mathrm{e}}=\frac{\mathrm{C}_{0}-\mathrm{C}_{\mathrm{e}}}{\mathrm{m}} \mathrm{V}
$$

Onde: $\mathrm{q}_{\mathrm{e}}$ é a capacidade de adsorção, $\mathrm{C}_{0}$ é a concentração inicial de corante, $\mathrm{C}_{\mathrm{e}}$ é a concentração de corante no tempo, $m$ é a massa de adsorvente e $V$ é o volume da solução.

\subsection{Isotermas e termodinâmica}

Foram usados dois modelos para o ajuste das isotermas de adsorção, BET e Freundlich (Brunauer, Emmett e Teller, 1938), equações 2 e 3, respectivamente:

$$
\mathrm{q}_{\mathrm{e}}=\frac{\mathrm{q}_{\mathrm{Bet}} \cdot \mathrm{k}_{1} \cdot \mathrm{C}_{\mathrm{e}}}{\left(1-\mathrm{k}_{2} \cdot \mathrm{C}_{\mathrm{e}}\right) \cdot\left(\left(1-\mathrm{k}_{2} \cdot \mathrm{C}_{\mathrm{e}}+\mathrm{k}_{1} \cdot \mathrm{C}_{\mathrm{e}}\right)\right.}
$$




$$
\mathrm{q}_{\mathrm{e}}=\mathrm{K}_{\mathrm{F}} \cdot \mathrm{C}_{\mathrm{e}^{\frac{1}{\mathrm{n}}}}
$$

Onde $\mathrm{q}_{\mathrm{e}}$ é a quantidade adsorvida por massa de adsorvente no equilíbrio, $\mathrm{C}_{\mathrm{e}}$, a concentração de equilíbrio, qBet é a capacidade de adsorção na monocamada, $K_{1}$ e $K_{2}$ são constantes do $\mathrm{BET}, n$ é o parâmetro do modelo de Freundlich e $\mathrm{K}_{\mathrm{F}}$ é a constante de Freundlich.

Para os cálculos da termodinâmica de adsorção foram utilizadas as equações 4 e 5 (Milonjic, 2007):

$$
\begin{aligned}
& \Delta \mathrm{G}=-\mathrm{RT} \ln (\mathrm{k}) \\
& \ln (\mathrm{k})=\frac{-\Delta \mathrm{H}}{\mathrm{RT}}+\frac{\Delta \mathrm{S}}{\mathrm{R}}
\end{aligned}
$$

\section{RESULTADOS E DISCUSSÃO}

\subsection{Caracterização MEV e BET}

A partir da análise MEV foi possível identificar a diferença entre a sílica padrão e sílica modificada, como mostra a Figura 1.

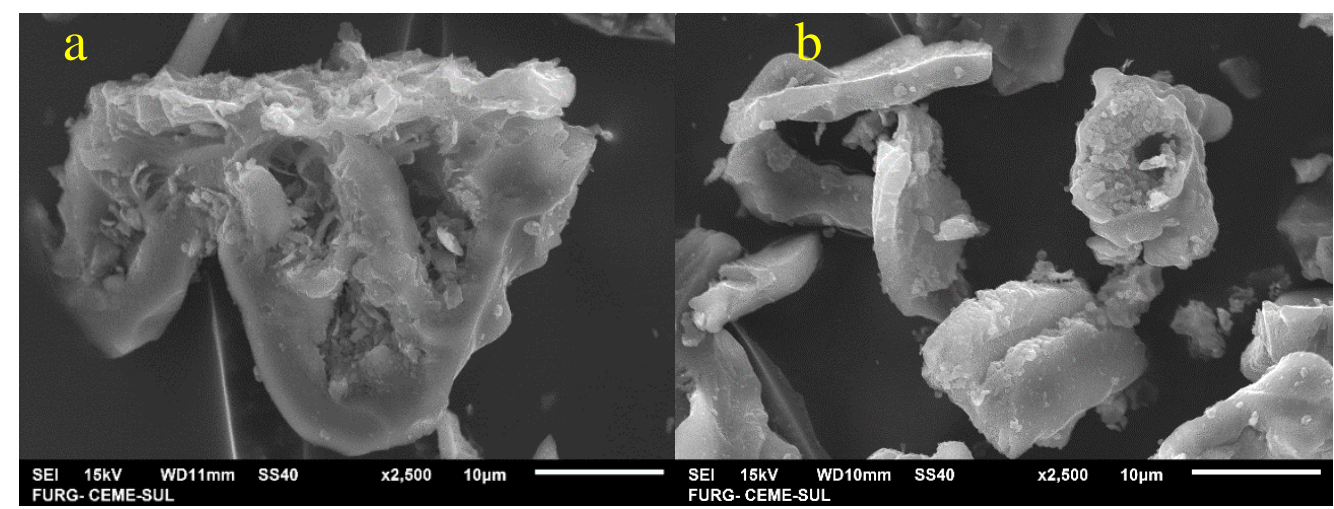

Figura 1 - Microscopia eletrônica de varredura (MEV) para sílica. a) Padrão; b) Modificada com ultrassom.

De acordo com as imagens do MEV, a lixiviação através do ultrassom aumentou a área superficial, fato este comprovado pelos dados do BET (Tabela 1). Isto ocorreu, devido a forma de transferência de massa e calor que aconteceu na lixiviação ultrassom, acarretando uma maior decomposição das partículas e no aumento da área superficial das partículas de sílica. Além disso, é possível observar os menores tamanhos de partícula de sílica produzida através do ultrassom como mostrado na Figura 1. Tais características, como menor tamanho de partícula e maior área superficial são essenciais para a obtenção de adsorventes.

Através dos dados da Tabela 1, verificou-se que a modificação através de ultrassom propiciou um aumento na área superficial, porém um diâmetro de poros menor. O fator predominante na adsorção do violeta cristal é a área superficial, como comprovado pelos resultados de adsorção apresentados nas Figuras 2 e 3. 
Tabela 1 - Dados de caracterização através do analisador de área superficial (BET).

\begin{tabular}{ccc}
\hline & Padrão & $\begin{array}{c}\text { Modificação } \\
\text { com ultrassom }\end{array}$ \\
\hline $\begin{array}{c}\text { Area superficial } \\
\text { BET }\left(\mathrm{m}^{2} \mathrm{~g}^{-1}\right)\end{array}$ & $71,97 \pm 1,22$ & $91,05 \pm 1,94$ \\
$\begin{array}{c}\text { Diâmetro médio } \\
\text { dos poros (nm) }\end{array}$ & $11,22 \pm 0,20$ & $8,44 \pm 0,12$ \\
\hline
\end{tabular}

\subsection{Efeito da temperatura}

A partir dos dados obtidos com a variação da temperatura nas concentrações estipuladas, foram traçadas as isotermas de adsorção no equilíbrio para a sílica padrão e a sílica modificada com ultrassom. As isotermas estão apresentadas nas Figuras 2 e 3.

Figura 2- Isotermas de adsorção de cristal violeta em sílica padrão

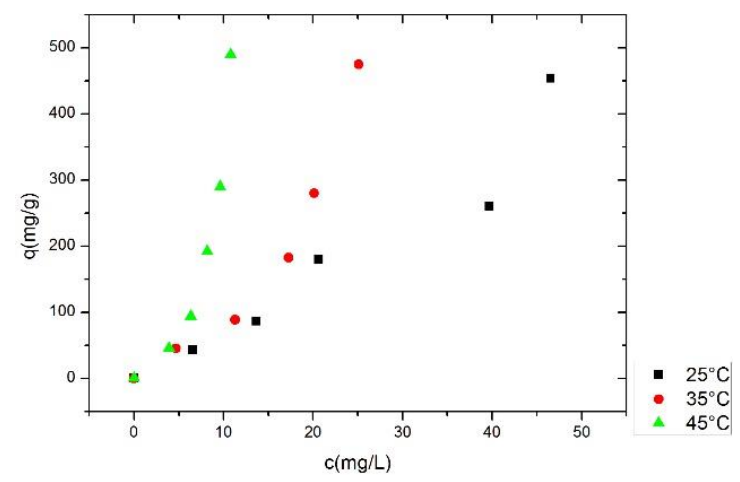

Figura 3- Isotermas de adsorção de cristal violeta em sílica modificada com ultrassom.

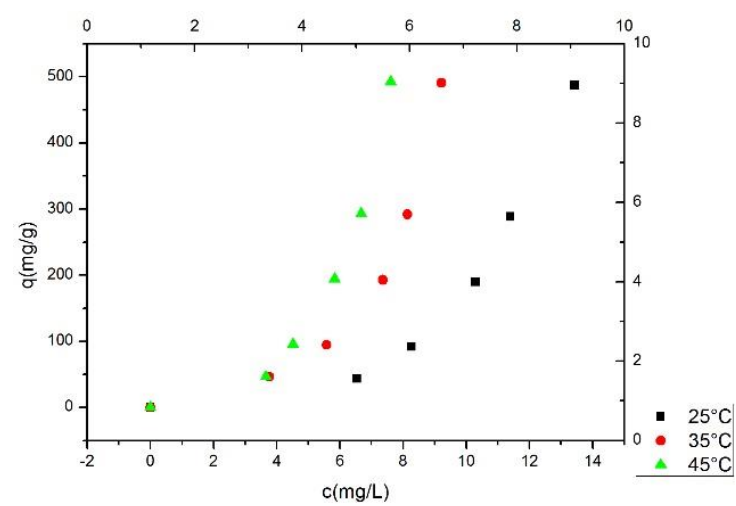

É possível observar que o aumento da temperatura favoreceu a adsorção. Em ambos adsorventes, obteve-se o maior rendimento em $45^{\circ} \mathrm{C}$. Porém, a sílica modificada com ultrassom apresentou resultados ainda melhores chegando a quantidade adsorvida de 492,39 $\mathrm{mg} \mathrm{g}^{-1}$ enquanto a sílica padrão alcançou 489,2 $\mathrm{mg} \mathrm{g}^{-1}$ nas mesmas condições. Essa diferença entre as capacidades de adsorção ocorre devido a maior área superficial da sílica modificada, demonstrando a eficiência do processo de lixiviação via ultrassom. 


\section{Congresso Brasileiro de Engenharia Química \\ em Iniciação Científica \\ UFSCar - São Carlos - SP \\ 16 a 19 de Julho de 2017}

As isotermas foram traçadas de acordo com os modelos de Freundlich e BET. Os resultados estão descritos na tabela 2. Para ambos os modelos, verificou-se valores altos de $\mathrm{R}^{2}$, exceto nas temperaturas de 298 e $308 \mathrm{~K}$ para o modelo de Freundlich. Assim, optou-se pelo modelo BET para representar os dados experimentais.

Tabela 2 - Ajustes de modelos de Freundlich e BET

\begin{tabular}{ccccccc}
\hline Adsorvente & \multicolumn{3}{c}{ Padrão } & \multicolumn{3}{c}{ Modificada } \\
\hline Freundlich & $\mathbf{2 9 8 K}$ & $\mathbf{3 0 8 K}$ & $\mathbf{3 1 8 K}$ & $\mathbf{2 9 8 K}$ & $\mathbf{3 0 8 K}$ & $\mathbf{3 1 8 K}$ \\
\hline $\mathrm{kF}(\mathrm{mg} / \mathrm{g})(\mathrm{mg} / \mathrm{L})^{-1 / n f}$ & $4,19 \mathrm{E}-11$ & $2,016 \mathrm{E}-5$ & 0,1779 & 0,06922 & 0,1291 & 0,4926 \\
$1 / \mathrm{nF}$ & 0,1277 & 0,1891 & 0,3016 & 0,2931 & 0,2601 & 0,2945 \\
$\mathrm{R}^{2}$ & 0,7712 & 0,8720 & 0,9920 & 0,9995 & 0,9948 & 0,9983 \\
\hline BET $^{2}$ & $\mathbf{2 9 8 K}$ & $\mathbf{3 0 8 K}$ & $\mathbf{3 1 8 K}$ & $\mathbf{2 9 8 K}$ & $\mathbf{3 0 8 K}$ & $\mathbf{3 1 8 K}$ \\
\hline $\mathrm{K}_{1}\left(\mathrm{~L} \mathrm{mg}^{-1}\right)$ & 0,1548 & 0,0208 & 0,0706 & 0,0559 & 0,4288 & 0,2381 \\
$\mathrm{~K}_{2}\left(\mathrm{~L} \mathrm{mg}^{-1}\right)$ & 0,0167 & 0,0264 & 0,0752 & 0,0688 & 0,0895 & 0,1043 \\
$\mathrm{qBET}_{\mathrm{BET}}\left(\mathrm{mg} \mathrm{g}^{-1}\right)$ & 102,1 & 266,24 & 115,21 & 153,21 & 88,32 & 111,95 \\
$\mathrm{R}^{2}$ & 0,9866 & 0,9982 & 0,9992 & 0,9613 & 0,9628 & 0,9642 \\
\hline
\end{tabular}

\subsection{Termodinâmica}

A termodinâmica pode ser analisada a partir das equações 4 e 5. Os resultados obtidos estão descritos nas tabelas 2 e 3.

Tabela 3- Parâmetros termodinâmicos da sílica padrão

\begin{tabular}{cccc}
\hline Temperatura $(\mathrm{K})$ & $\Delta \mathrm{G}^{\circ}\left(\mathrm{kJ} \mathrm{mol}^{-1}\right)$ & $\Delta{\mathrm{H}\left(\mathrm{kJ} \mathrm{mol}^{-1}\right)}$ & $\Delta \mathrm{S}\left(\mathrm{kJ} \mathrm{mol}^{-1} \mathrm{~K}^{-1}\right)$ \\
\hline 298,15 & $-6,842$ & 25,62 & 1,411 \\
308,15 & $-4,385$ & & \\
318,15 & $-5,544$ & & \\
328,15 & $-6,328$ & & \\
\hline
\end{tabular}

Tabela 4- Parâmetros termodinâmicos da sílica modificada por ultrassom

\begin{tabular}{cccc}
\hline Temperatura $(\mathrm{K})$ & $\Delta G^{\circ}\left(\mathrm{kJ} \mathrm{mol}^{-1}\right)$ & $\Delta \mathrm{H}\left(\mathrm{kJ} \mathrm{mol}^{-1}\right)$ & $\Delta \mathrm{S}\left(\mathrm{kJ} \mathrm{mol}^{-1} \mathrm{~K}^{-1}\right)$ \\
\hline 298,15 & $-5,323$ & 31,19 & 1,781 \\
308,15 & $-9,311$ & & \\
318,15 & $-8,683$ & & \\
328,15 & $-8,728$ & & \\
\hline
\end{tabular}

De acordo com as tabelas 3 e 4 , os valores de $\Delta G^{\circ}$ indicam que o processo foi espontâneo e favorável. Os maiores valores negativos de $\Delta \mathrm{G}^{\circ}$ indicam que a adsorção foi mais favorável em temperaturas elevadas. A variação de entalpia é positiva, mostrando que a adsorção foi um processo endotérmico.

\section{CONCLUSÃO}


A partir da análise dos dados obtidos experimentalmente verificou-se que o uso do ultrassom na preparação da sílica forneceu um material com melhores características adsorventes. A área superficial específica aumentou em $30 \%$ em relação ao processo convencional. As análises de BET e SEM mostraram que o tratamento com ultrassom aumentou a área superficial do adsorvente e permitiu maior retenção do corante. A adsorção foi favorecida na temperatura de $45^{\circ} \mathrm{C}$ e em altas concentrações. Os parâmetros termodinâmicos indicaram que processo foi espontâneo, favorável e endotérmico. Dessa forma, a sílica tratada com ultrassom se apresentou mais eficiente na remoção do corante violeta cristal de soluções do que a sílica padrão.

\section{REFERÊNCIAS}

ABRAFATI, Indicadores do setor de tintas, 2015. Disponível em: http://www.abrafati.com.br/indicadores-do-mercado/numeros-do-setor/. Acesso em: Junho/2016.

BRUNAUER S.; EMMETT P.H.; TELLER E.; Adsorption of gases in multimolecular layers, J. Am. Chem. Soc. 60 (1938) 309-318.

CHIOU M.S.; HO P.Y.; LI H.Y, Adsorption of anionic dyes in acid solutions using chemically cross-linked chitosan beads, J. Dyes Pig. pag 69-84, 2004.

FOLETTO, E.L. et al; Aplicabilidade das cinzas da casca de arroz. Química Nova, v. 28, n.6, p.1055-1060, 2005

INSTITUTO RIO GRANDENSE DE ARROZ. Evolução da produção e produtividade de arroz, 2015. Disponível em: http://www.irga.rs.gov.br/upload/2015 0720141753producao_rs_e_brasil_grafico.pdf. Acesso em: Junho/2016

MILONJIC, S. K.; A consideration of the correct calculation of thermodynamic parameters of adsorption. Journal of the Serbian Chemical Society, 72, 1363-1367 (2007).

QUADROS, S. S. Tratamento e reutilização de efluentes têxteis gerados nos tingimentos de tecido de algodão. p. 15-16. Blumenau, 2005.

SANTOS, A. J. M. et. al. Estudo da retenção de corante violeta cristal em quitosana. Cuiaté, 2012.

WEBER J, et al. The effect of anion adsorption on the kinetics of the $\mathrm{Fe} 3 \mathrm{p} / \mathrm{Fe}$ ] reaction on Pt and Au electrodes in HCIO4. J Electroanal Chem Interfacial Electrochem, 1978.

XIONG, L. et al; Burning Temperature Dependence of Rice Husk Ashes in Structure and Property, Frontier Materials Lab, Research Center for Advanced Photon Technology, Toyota Technological Institute, Japan 